\title{
JOGADORES DE FUTEBOL NO BRASIL: MERCADO, FORMAÇÃO DE ATLETAS E ESCOLA'
}

\author{
DR. ANTONIO JORGE GONÇALVES SOARES \\ Doutor em Educação Física (UGF) e professor do Programa de Pós-graduação em Educação (UFRJ) \\ (Rio de Janeiro - Rio de Janeiro - Brasil) \\ E-mail: ajsoares@globo.com
}
MS. LEONARDO BERNARDES SILVA DE MELO
Mestre em Educação Física - UGF
(Rio de Janeiro - Rio de Janeiro - Brasil)
E-mail: leonardo.melo@globo.com

\section{MS. FELIPE RODRIGUES DA COSTA}

Mestre em Educação Física - UFES, doutorando do Programa de

Pós-graduação em Educação Física - UGF (Doutorado)

(Rio de Janeiro - Rio de Janeiro - Brasil)

E-mail: fcostavix@gmail.com

\section{MS. TIAGO LISBOA BARTHOLO}

Mestre em Educação Física - UGF, professor do Colégio de Aplicação da UFRJ,

aluno do Programa de Pós-graduação em Educação - UFRJ

(Rio de Janeiro - Rio de Janeiro - Brasil)

E-mail: tbartholo8I@hotmail.com

\section{DR. JORGE OLÍMPIO BENTO}

Doutor e Professor Catedrático da Faculdade de Desporto, Universidade do Porto

(Porto - Porto - Portugal)

E-mail: jbento@fade.up.pt

\begin{abstract}
RESUMO
O objetivo do estudo é refletir sobre a relação entre a profissionalização no futebol e a escolarização. O Brasil exportou para o exterior nos últimos seis anos 6.648 jogadores. Deste contingente emigraram para Europa 3.593, isto é, 54,0\% do total. Argumentamos que estamos diante de uma agência que: recruta jovens do sexo masculino, em geral das camadas populares, para atuarem no mercado interno ou externo do futebol; e se configura num tipo de negócio que dá base à criação de uma indústria de formação profissional, que pode estar em competição com a escolarização básica dos jovens aspirantes a atletas profissionais.
\end{abstract}

PALAVRAS-CHAVE: Futebol; educação; formação de jovens jogadores; escola.

I. Agradecemos o apoio financeiro da CAPES, do CNPq e da FAPERJ. 
Os estudos sobre os processos de detecção e treinamento de talentos no futebol indicam que o mercado desse esporte tem como suporte um novo tipo de agência de formação profissional que recruta jovens adolescentes, em geral, pertencentes às camadas populares e médias (DAMO, 2005; RIAL, 2006; PAOLI, 2007). Esses jovens investem tempo significativo de suas vidas nessa carreira e possuem como horizonte um mercado altamente competitivo, com poucos postos de trabalho valorizados economicamente.

A formação no futebol pode se iniciar a partir dos 12 anos de idade, muitas das vezes em regime de albergamento, e tem uma duração aproximada entre 5.000 e 6000 horas de trabalho voltado para preparo físico e para o domínio de técnicas corporais e psicológicas (DAMO, 2005; MELO, 20I0). Essa carreira exige extenuante trabalho corporal para aqueles que pretendem entrar nesse afunilado mercado. Todavia, é nesse mesmo período da vida que a Educação Básica, em tese, exige do jovem dedicação na incorporação de capital cultural para que possa ser uma das chaves de acesso ao mercado de trabalho. Em outras palavras, estamos falando da possibilidade de reconversão do capital cultural, em seus diferentes estados, em capital econômico, no sentido de Bourdieu (1998).

A luta dos jovens que vislumbram a carreira de jogador de futebol, os seus sonhos e frustrações tem sido objeto do cinema, da televisão e dos jornais, mas não tem recebido a mesma atenção das pesquisas sobre a formação profissional no esporte no campo da educação, da educação física e da sociologia das profissões. Observemos que essa agência de formação profissional de jovens para o futebol tem operado no Brasil (MELO, 20 I0) e em outros países sem nenhuma orientação de política governamental, ou com ações pouco efetivas (CHRISTENSEN; SØRENSEN, 2009).

A partir da consulta a literatura sobre o tema, problematizamos nesse texto a articulação entre o mercado, a formação no futebol e a escolarização de jovens atletas. A finalidade aqui não é fornecer respostas normativas para a questão levantada, o intuito é desnaturalizar o processo de formação de atletas para o futebol e colocar em evidência dados e questões para pensarmos que esse esporte é um dos projetos de vida apresentados para parte da juventude em nosso país.

\section{O MERCADO DOS JOGADORES DE FUTEBOL}

O futebol como espaço de identificações (locais e nacionais) estruturou-se na configuração dos Estados nacionais a partir do final do século XIX como fruto da expansão capitalista e dos projetos de modernização, nem sempre consensuais 
ou planejados (MANDELL, 1984; GUTTMANN, 1994; SOARES; LOVISOLO, 2003; POLI, 2006).

Se o processo de identificação coletiva pelo futebol se deu inicialmente como local de construção de sentimentos nacionais e locais, rapidamente tais sentimentos identitários se tornaram um valor agregado aos produtos e corpos no mercado dos esportes. Tais identidades, para além da produção dos sentimentos de coesão ou dissensão, podem ser transformadas em valor agregado aos produtos disponíveis no mercado (MACHADO, 2004; BARTHOLO; SOARES, 2006). O mercado entre os estados nacionais, seja pela transação de matéria prima, de produtos e de serviços especializados ou culturais, foi um espaço privilegiado de negociação e embates simbólicos e/ou econômicos entre os diferentes povos. Observe-se que as identidades são construções simbólicas e normativas, situadas relacionalmente no espaço contestado da cultura (CUCHE, 1999; MACHADO, 2004).

Nessa direção, a popularização desse esporte na América Latina se deu no cenário dos embates de classes e dos interesses de grupos em dominar politicamente as instituições esportivas. Desde cedo, o futebol anunciava-se como local estratégico para acumular capital político, como ocupação remunerada para as camadas populares e como indústria do espetáculo, na medida em que atraía multidões nas duas primeiras décadas do Séc. XX (PEREIRA, 2000). Não se pode esquecer que todo esse movimento estava ancorado nas diferentes interpretações culturais sobre os valores civilizatórios e educacionais do esporte. Esportes como o futebol em países como Argentina e Brasil e o beisebol em Cuba, além de estarem atrelados ao projeto de modernização dessas sociedades, foram percebidos como "juego[s] moderno[s] y democrático[s] que posibilitaba[n] a los jugadores jóvenes de orígenes modestos, la experiencia de la mobilidade social" (ARCHETTI, 2003, p. 260).

Nesse sentido, o futebol possibilitou que os países da América Latina participassem do mercado das nações ${ }^{2}$ para além do fornecimento de matéria prima. Nesse mercado transnacional das identidades nacionais ${ }^{3}$, países como Brasil, Argentina e Cuba teriam se notabilizado desde cedo por exportar corpos, ritmos e comidas exóticas (ARCHETTI, 2003).

O processo de transferência e negociação de jogadores entre os principais produtores de futebolistas da América Latina e a Europa ocorreu durante boa parte

2. A estrutura da Federação Internacional de Futebol Associação (Fifa), principalmente durante a gestão de Jules Rimet ( 192 I - 1954), internacionalizou-se e acabou por organizar um mercado transnacional do esporte. A Fifa hoje congrega 208 associações afiliadas no mundo. Disponível em: http://www. fifa.com/aboutfifa/federation/associations.html .

3. Não é objetivo desse ensaio debater as teorias de identidade que atravessam o campo esportivo. Aqui entendemos que os discursos identitários servem como valor agregado a produtos, pessoas e grupos que circulam para além do local. 
do século $X X$. Todavia, esse processo intensificou-se no último quartel do século anterior e, nos últimos anos, o fluxo migratório aumentou, configurando uma verdadeira indústria de exportação de serviços especializados. A crescente demanda de transferências de jogadores brasileiros para o exterior é produto de vários fatores, a saber: o limite de empregabilidade do mercado do interno; os interesses competitivos e financeiros dos clubes estrangeiros com maior capital financeiro; a relação custo/ benefício na importação desses serviços especializados; a formação de um corpo de empresários ávidos a realizar negócios nos diferentes países, credenciados ou não pela FIFA; e o mecanismo de solidariedade criado pela FIFA, no ano de $200 \mathrm{I}^{4}$.

A criação da Lei Pelé e o caso Bosman na Europa instituem novas regras para as transações comerciais dos jogadores, e modifica o cenário de renegociação de contratos (MCGILLIVRAY; MCNTOSH, 2006). Essa mudança criou facilidades e benefícios para todos os atores envolvidos nas transações. Em outras palavras, há ganhos financeiros para todas as partes envolvidas em cada negociação: jogadores, empresários, clubes, patrocinadores, entre outros. $\bigcirc$ argumento romântico que afirma que os jogadores no passado tinham "amor à camisa" ou ficavam anos no mesmo clube por "amor ao clube" deve ser analisado a partir das novas regras e demandas do mercado.

O fluxo de jogadores para o exterior e a centralidade financeira do futebol europeu, captando jogadores dos diferentes países, são temas de algumas análises no Brasil (HELAL, 1997; PRONI, 2000; DAMO, 2005; LEONCINI; SILVA, 2005; ALCANTARA, 2006; CARVALHO; GONÇALVES, 2006; SOUTO, 2004). Em geral, as análises apontam para:

I) o problema da administração amadora e patrimonialista dos clubes brasileiros e a consequente resistência à adoção de uma administração racional;

2) a nova relação de trabalho entre clubes e jogadores com a promulgação da Lei Pelé (lei n. 9.615, de 24 de março de 1998), que extinguiu a figura jurídica do passe

4. O mecanismo de solidariedade estimula a formação de mão de obra para o mercado profissional. A nova legislação recompensa financeiramente todos os clubes formadores por onde o atleta passou dos 12 aos 23 anos com 5\% do valor bruto das transações (0,25\% da transferência por cada ano de formação entre os 12 e os 15 anos; 0,5\% por cada ano dos 16 aos 23). Notemos que esse mecanismo estimula a continuidade do sistema atual, pois, em alguma medida, distribui os ganhos com a venda do atleta. Todos ganham: jogador, empresários, clube formador, grandes clubes importadores que continuam a captar talentos descobertos em diversos países.

5. Mudanças foram introduzidas pela lei $9.98 \mathrm{I} / 00$, pela medida provisória $\mathrm{n} .2 .14 \mathrm{I} / 0 \mathrm{I}$ e, por último, pela lei $n$. 10.672/03. Tais mudanças tentaram atenuar os efeitos produzidos pela Lei Pelé. Desde o caso Bosman, na década de 1990, julgado na Corte do tribunal da Comunidade Européia, a figura jurídica do "passe" passou a ter seus dias contados. 
3) a centralidade da figura do empresário e do agente ${ }^{6}$ nessa nova configuração de mercado;

4) a limitação de postos de trabalho para jogadores no mercado brasileiro;

5) o surgimento de uma "indústria" de formação de jogadores”;

6) os baixos salários em termos médios no mercado do futebol brasileiro.

Como os três primeiros itens já foram exaustivamente analisados pelos autores supracitados, nos concentraremos nos três últimos.

Note-se que as negociações de jogadores de futebol para o exterior reforçaram as estatísticas das exportações:

O negócio futebol tem peso considerável na exportação brasileira. As vendas de jogadores estão entre os serviços exportados pelo país que apresentou aumento de $34 \%$ em 2005 (cerca de US\$ 6 bilhões). Esse grupo de serviços representa 40\% das exportações brasileiras (toda a exportação brasileira de serviços gerou US\$16 bilhões em 2005) (ALCANTARA, 2006, p. 299).

Esses dados constam das operações registradas no Banco Central (BC), dentro da rubrica de serviços empresariais, profissionais e outros técnicos. O fenômeno de migração de jogadores aponta para um alto grau de conectividade e integração no mercado global do futebol, mas há de se destacar que esse fenômeno faz parte de um movimento mais amplo do processo migratório e econômico entre os países pobres e os ricos a partir dos anos de 1980 (COGO, 2002; BAENINGER, 2003; HALL, 2003; DIETSCHY, 2006; FUSCO, 2006).

Esse cenário criou um tipo específico de produção de jogadores que visa prioritariamente o mercado exterior. Os jovens recrutados para os centros formadores passam a ter como meta profissional a emigração para outros países. As faixas salariais variam e há uma hierarquia de acordo com os mercados que têm mais visibilidade midiática e prestígio junto aos torcedores/consumidores. Nesse mercado global temos um modelo que possui um núcleo composto por outras camadas externas. No centro do mercado temos os países europeus - principalmente Alemanha, Itália, Inglaterra, França, Espanha e Portugal - que são o grande destino dos trabalhadores emigrantes do futebol. Ao redor desse núcleo temos respectivamente as Américas

6. A FIFA promove Cursos para Agentes de Futebol por meio de suas afiliadas. No Brasil temos mais ou menos 327 agentes credenciados. Observe-se que nos últimos dois anos ocorreu um aumento de mais de 100\% do número de agentes FIFA no Brasil. Ver regulamento para tornar-se agente em $<$ www.fifa.com $>$

7. A legislação trabalhista brasileira impõe que o contrato de trabalho só pode ser assinado a partir dos 16 anos. É prática no meio assinar contratos, mesmo sem validade legal (mas que possuem eficácia simbólica), com jovens talentos que ainda não atingiram essa idade. 
do Sul e Central, seguidas do continente africano e fechando o círculo a Oceania, Ásia e América do Norte. Este modelo está baseado no poder econômico dos clubes de futebol que contratam os atletas e no sucesso doméstico das ligas de futebol (MAGEE; SUGDEN, 2002; DABSCHECK, 2006). ${ }^{8}$

Durante o período de 2003 a 2009 emigraram para o exterior 6.648 jogadores brasileiros. Desse montante, o continente europeu foi o que recebeu mais futebolistas: 3.593 , número que representa 54,0\% de todas as transferências realizadas para o exterior. $\bigcirc$ continente asiático foi o segundo maior importador com 23,0\% das transferências, totalizando 1.528 jogadores. Com pouco mais de $10 \%$, a América do Sul é o terceiro maior destino dos jogadores brasileiros, com 694 atletas transferidos no período. Os demais continentes não são os destinos preferidos dos brasileiros, como é demonstrado pelos números apresentados: América Central (2,8\%), América do Norte (3,4\%), África ( I ,7\%), Oceania (0,6\%) e os países transcontinentais $(4,1 \%){ }^{9}$

Se o número de jogadores que saem do Brasil todos os anos é significativo, a taxa de retorno também o é. Em 2005 saíram do País 804 jogadores, sendo 54,8\% para a Europa. Durante o mesmo ano retornaram 49| atletas, dos quais 48,0\% retornavam do continente europeu. Em 2006, a taxa de retorno diminuiu: dos 85 I atletas que emigraram, 3 I I voltaram ao País. Os números de transferências de jogadores brasileiros para o mercado internacional do futebol evidenciam que esse mercado está aquecido com um aumento progressivo de negociações. No ano de 2007 foram 1085 transferências com o retorno de 489 jogadores ao mercado interno e, em 2008, um total de 1176 novos atletas se colocou no mercado internacional e 659 jogadores retornaram ao país.

Segundo estimativas da CBF, cerca de $25 \%$ dos jogadores brasileiros que emigram vão para países sem nenhuma tradição futebolística, e que o número de atletas que deixaram o país entre 1992 e 2005 teve um aumento de 392\% (JACOBS; DUARTE, 2006). Mesmo aqueles que vão jogar em países periféricos ao mercado desse esporte, os salários negociados são melhores que os obtidos em clubes com baixo poder econômico no Brasil.

Jacobs e Duarte (2006) relatam a história de um jogador que recebia cerca de 730 dólares para jogar em um clube da segunda divisão do Paraná. Seu empresário

8. Além do investimento de empresários brasileiros na seleção, treinamento e transferência de jovens talentos para os mercados internacionais, há também o investimento estrangeiro na captação de recursos humanos em países como Brasil e África do Sul. O investimento em países com níveis baixos de Índice de Desenvolvimento Humano (IDH) se constitui numa estratégia dos investidores.

9. Dados e percentuais construídos a partir da lista de transferências da CBF. Disponível em: <www. cbf.com.br> 
conseguiu um emprego em um clube de futebol no Brunei com um salário de quatro mil dólares mensais e ainda 500 dólares de prêmio em caso de vitória ou empate de sua equipe. A transferência foi concretizada uma vez que a remuneração era oito vezes maior - nos valores da época - ao salário de sua equipe no campeonato do Paraná.

Esses dados mostram que o fluxo de emigração de jogadores brasileiros para o exterior se tornou um dos objetivos dessa "indústria" ou agência de formação profissional de jovens em nossa sociedade. Cabe ressaltar que, a ampliação dos postos de trabalho, com as novas perspectivas do mercado internacional, aumenta a demanda por jovens dispostos a ingressar no regime de treinamento nos clubes de futebol. Com isso temos uma indústria de formação de jogadores no Brasil para atender o mercado interno e externo no qual a matéria prima em geral são jovens entre os 12 e 16 anos de idade. Até aqui estamos descrevendo como o mercado do futebol se hierarquizou e se integrou, o que criou a necessidade de formação de jogadores para atender a demanda interna e externa.

\section{POSTOS DE TRABALHO, REMUNERAÇÃO E POSSIBILIDADES DE MOBILIDADE}

O mercado para jogadores no Brasil, apesar de os dados não serem precisos, está estimado entre 10 a 15 mil postos de trabalho. Parte desses postos são empregos sazonais e bastante precários. $\bigcirc$ Brasil tem cerca de 800 clubes de futebol credenciados às subsidiárias da FIFA (DAMO, 2007). Poder-se-ia pensar que esse número é expressivo em se tratando dos postos principais de trabalho nessa indústria do espetáculo, mas algumas ressalvas devem ser feitas.

Dos 800 clubes credenciados apenas 2,5\%, isto é, 20 clubes, detêm $90 \%$ da preferência dos torcedores (DAMO, 2007). Isso indica que o potencial de exploração do produto que os clubes podem vender junto ao público consumidor (torcedores) é desigual e acarreta uma redução significativa dos postos de trabalho bem remunerados. Se calcularmos que um clube possui em média 26 jogadores na sua equipe principal, teríamos em torno de 520 postos de trabalho na parte mais valorizada do mercado, isto é, os 20 principais clubes no Brasil que disputam o campeonato nacional da primeira divisão.

Os salários de jogadores no Brasil são baixos se considerarmos os sonhos de mobilidade social e econômica dos jovens, em sua maioria oriundos das camadas populares e médias. A pirâmide salarial dos jogadores profissionais no Brasil não mudou muito nos últimos oito anos. Os dados divulgados pela Confederação Brasileira de Futebol (CBF) em 1999 indicavam que 51,6\% dos jogadores recebiam até um salário mínimo, e 33,2\% até dois salários mínimos; se somados esses percentuais 
podemos pensar que $84,8 \%$ dos jogadores recebiam salários até dois salários mínimos; acima de dez salários mínimos apenas 5,2\% (PRONI, 2000). $\bigcirc$ ano de 2003, por exemplo, revela a seguinte distribuição: $82,41 \%$ recebem entre um e dois salários mínimos, 2,05\% entre 10 e 20 e apenas 3,57\% acima de 20 salários mínimos (HELAL, 1997; HELAL; SOARES; SALLES, 2005). Os dados disponibilizados em 2009 pela CBF mostram que 84\% dos jogadores, de todas as divisões do futebol profissional no Brasil, recebem salários até $1.000,00$ reais, 13\% recebem entre 1000 e 9000 reais e apenas 3\% recebem acima de 9000 reais por mês ${ }^{10}$.

A pirâmide salarial do futebol brasileiro está longe de ser o oásis da riqueza ou da mobilidade econômica tão sonhada pelos jovens brasileiros. Contudo, esses dados, quando divulgados na mídia" ', parecem não desestimular a busca pela profissionalização no futebol. Poder-se-ia pensar que o sonho dos jovens que estão atuando nas categorias de base, de ser um "Kaká" ou qualquer outro famoso jogador que atua na Europa, está longe das estatísticas positivas de riqueza nesse mercado. Embora a Europa seja o maior destino de nossos jogadores, esse mercado não é só formado por ligas e clubes com alto potencial de remuneração econômica. $\bigcirc$ destino de muitos desses jovens são as divisões inferiores do futebol brasileiro, centros alternativos da Europa (Suécia, Grécia, Albânia, Malta, Bélgica, etc.) ou em países em que a remuneração está longe do imaginário dos altos salários do futebol.

A questão que se coloca é a seguinte: o destino da maioria dos jovens brasileiros que se dedicam intensamente a carreira de jogador seria diferente, em termos econômicos, se realizassem seus investimentos na escolarização básica? Não temos respostas e nem dados seguros no momento para dizer o que seria mais rentável economicamente em médio e longo prazo para esses jovens. A teoria social indica que a origem familiar da maioria dos atletas e a escolarização de seus pais, em termos de probabilidade, execerceriam uma forte pressão para eles permanecerem próximos aos estratos em que se encontram suas famílias na estratificação social (BOURDIEU, 1998; SCHWARTZMAN, 2004; 2006). Assim, o futebol torna-se para os membros das camadas populares e médias uma aposta que pode mudar o destino econômico do indivíduo e de sua família. Aduzido aos argumentos anteriores, a escola para as camadas populares está longe de ser o caminho da ascensão social para a maioria daqueles que completam o ensino fundamental (SEGNINI, 2000) 12 .

10. Confederação Brasileira de Futebol (CBF) em 2009 e amplamente divulgados pela mídia.

I I. Claro que essas informações circulam nas mídias mas não são enfatizadas, o destaque é dado as carreiras de sucesso financeiro e esportivo.

12. Liliana Rolfesen P. Segnini, professora da Faculdade de Educação (Unicamp), proferiu palestra intitulada "Trabalho e educação no Brasil contemporâneo", ocorrida no dia 29 de março de 2006. Nessa palestra a pesquisadora tomou o exemplo de Ronaldinho Gaúcho para demonstrar que ele 
Devemos ter clareza que os desejos construídos culturalmente são mais potentes que as oportunidades concretas oferecidas. Toledo (2002) indica que em média, menos de $1 \%$ dos aspirantes à profissão, são aproveitados nas "peneiradas" dos clubes (teste para a seleção de atletas nas divisões de base). Em 1995, por exemplo, de 3.500 garotos que aventuraram nas peneiras do São Paulo Futebol Clube, apenas cinco foram aproveitados; no ano seguinte, apenas dois de 4.000 permaneceram no clube. Damo (2005) aponta semelhante relação candidato/vaga no Sport Club Internacional em 2004. Apesar disso é alta a demanda dos aspirantes a atletas de futebol.

Melo (20 I 0$)$ indica que no mercado de formação de atletas parte dos jovens podem receber, a partir dos 15 anos ou antes, salários ${ }^{13}$ com valores semelhantes ou superiores ao dos pais. Esse fato pode representar, aindo no momento da formação, certa mobilidade econômica e prestígio social para o jovem se comparado às ocupações mal remuneradas e pouco valorizadas dos seus responsáveis. Damo (2005, p. 269) descreve que a política do Sport Club Internacional (Porto Alegre) fixa um teto de ajuda de custo para os meninos das diferentes categorias de base: "aproximadamente 200 dólares para os meninos do Infantil, mas são raros os que dispõem desse montante como ajuda de custo; 300 para o juvenil e 400 dólares para os juniores"; mas existiriam entre esses aqueles que recebem salários altos quando apresentam maior "potencial" no esporte. Essa possibilidade pode transformar o futebol em projeto familiar de modo que as famílias de origem popular canalizem esforços e recursos para apoiar a carreira de seus filhos (RIAL, 2006). Queremos destacar, nesta seção, que parece existir uma desproporção entre as imagens de mobilidade econômica difundidas em nosso imaginário e os limites e restrições oferecidas pelo mercado do futebol no Brasil.

\section{FORMAÇÃO ESPORTIVA E ESCOLARIZAÇÃO}

Melo (20 I 0) indica que a carga horária que esses atletas em formação dedicam ao futebol em pouco difere do tempo dedicado para frequentar a escola. ${ }^{14} \mathrm{O}$ mesmo

representa uma exceção: é negro, com apenas oito anos de estudo e que os pais também possuem baixa escolaridade. Disponível em: <http://www.unicamp.br/unicamp/unicamp_hoje/jornalPDF/ ju3 I 8pg03.pdf>. Acesso em: 10 dez. 2006.

13. Schwartzman (2006) demonstra que a maioria dos trabalhadores infantis utiliza seus rendimentos com gastos pessoais.

14. O autor demonstra que o tempo de treinamento exigido para as categorias de base, desde o sub- 13 ao sub-20, pouco difere. O tempo semanal dedicado a escola (frequência as aulas e deslocamento) está em torno de 25 horas e para o futebol (treinamento, deslocamento e jogos) o tempo também está na casa das 25 semanais para todas as categorias. 
estudo indica que o tempo de treinamento nas categorias de base é semelhante ao das equipes profissionais, portanto, em termos práticos a carga horária de dedicação de adultos e aspirantes a atletas é a mesma. Como visto, a carga horária de treinos para formar um atleta é alta.

Para exemplificar, o atleta que começa na categoria mirim aos 12 anos (idade equivalente ao sexto ano escolar) se completasse o ensino médio aos 17 anos (quando estaria no último ano da categoria sub-17) teria tido, uma carga horária de 4.800 horas na escola contra 4.165 horas de treinamento no futebol, sem contarmos os jogos nos finais de semana. Isso nos permite vislumbrar o significado do tempo gasto para a formação no futebol (MELO, 2010, p. 2I).

Outro dado do mercado de formação de atletas é o processo migratório no país. Parte desses jovens que ingressam na carreira do futebol vem de outras cidades ou estados diferentes do clube formador. Isto significa que passam a residir separados de suas famílias e, se forem sendo aproveitados nas categorias subseqüentes, podem viver nessa condição até a profissionalização. ${ }^{15}$ Melo (20 I 0$)$ aponta que os atletas emigrantes, que vivem em regime de albergamento nos clubes do Rio de Janeiro, possuem maior número de reprovações e atraso escolar do que os atletas que residem com suas famílias.

A aposta na carreira de atleta requer diferentes renúncias nessa agitada fase da vida, considerando a extenuante demanda de trabalho corporal que pode, segundo Melo (20 I0), ultrapassar as seis mil horas de atividades ao longo do processo de formação. $O$ fato do tempo de dedicação à formação no futebol ser igual ou superior ao de dedicação à escola pode criar percalços no processo de escolarização. Por exemplo, os jogadores da categoria sub- I 5, treinam uma vez por dia, num dos turnos, e estudam no outro; a partir da categoria sub- 17 o clube pode programar treinos de manhã e à tarde. Isso conduz naturalmente que os atletas optem por frequentar a escola no período noturno. Melo (2010) indica que boa parte dos atletas que atua na categoria sub- 17 permanece na escola frequentando o ensino noturno (em torno dos 50\%), enquanto na categoria sub-20 esse número salta para $85 \%$ dos atletas. Nessa categoria a maioria faz ensino médio, uma pequena parte estuda no nível fundamental, alguns abandonaram a escola e poucos estão no ensino superior (MELO, 20 I0). O dado sobre o ensino noturno nas categorias sub- 17 e sub-20 sugere que essa concentração pode estar associada a maior dedicação do

15. Sportv-Repórter. Exploração de menores no futebol - "Granjas humanas" (Exibido em I 5//2/2007). Disponível em: <http://video.globo.com/Nideos/Player/Esportes/0,,GIM766709-7824 SPORTV + R EPORTER+INTEGRA+DO+PROGRAMA+DE,00.html >. Acesso em: I 3 jan. 2008. O referido programa revela a exploração dos menores no mercado do futebol. 
dia para as atividades relacionadas ao treinamento esportivo e a carreira. De fato, a partir dos 16 anos o atleta entra na fase crítica que determinará suas possibilidades no mercado.

O deslocamento dos atletas para o ensino noturno em si já indica que a dedicação à escolarização passa a secundária na vida desses jovens. $\bigcirc$ ensino noturno, para além dos problemas de infra-estrutura, de recursos humanos e gestão, possui um currículo que não leva em conta as peculiaridades do estudante-trabalhador (CORROCHANO; NAKANO, 2002). Se o estudante trabalhador que estuda à noite enfrenta problemas de concentração e dedicação aos estudo em função do cansaço físico, o atleta, que é também um trabalhador, enfrenta os mesmos problemas de cansaço físico pela carga de treinamento, além da dificuldade de frequentar com regularidade às aulas em função das constantes viagens para competições. Associado a isso, a dedicação ao esporte pode criar problemas de ordem subjetiva quando os atletas retiram o foco da vida escolar e dedicam-se à carreira quase que exclusivamente (CHRISTENSEN; SØRENSEN, 2009).

A relação entre escolarização e formação de atletas é um tema que ainda aparece num estágio inicial no campo das ciências sociais. Damo (2005) ao realizar um questionário junto aos alunos de escolas, públicas e privadas, de Porto Alegre, indica que um em cada três meninos pertencentes à escola pública deseja tornase jogador de futebol. A relação cai para metade quando olhamos para os dados das escolas privadas. Os dados construídos por Damo (2005) não apenas revelam uma exploração dessas representações sociais, pois, esses mesmos dados ratificam análises teóricas que indicam que, quanto menos capital cultural possuir o jovem no ambiente familiar, mais ele apostará em profissões ou carreiras que não dependam diretamente da escolarização. Outro indício nessa direção se encontra no estudo de Costa e Koslinski (2006) quando analisam as expectativas de escolarização e carreira futura entre alunos de escolas públicas e privadas de alto e baixo prestígio no Rio de Janeiro. ${ }^{16} \bigcirc$ estudo aponta que uma parte significativa dos alunos das escolas de baixo prestígio aspira ter profissões que não dependam do diploma do curso superior e, curiosamente, o esporte para esses aparece mais representado como expectativa de carreira do que para os alunos das escolas de alto prestígio. Poder-se-ia levantar a hipótese ${ }^{17}$ que a procura pela carreira esportiva pode estar relacionada com as expectativas de futuro proporcionadas pela escolarização e/ou

16. Os autores utilizam o conceito a partir do status que as escolas pesquisadas gozam no mercado escolar.

17. Testar essa hipótese requer realizar estudos que selecionem amostras significativas das diferentes modalidades esportivas com controle de variáveis sobre a escolarização do atleta e da família. 
pelo sucesso na vida escolar. Por outro lado, a educação escolar parece não ser fundamental para o sucesso na carreira de jogador de futebol.

Damo (2005) aponta que os centros de formação de atletas de futebol no Brasil, apesar dos limites legais, atuam sem nenhuma supervisão ou política pedagógica de estado. Esses centros são totalmente livres para definir as cargas de treinamento, escolher profissionais --com ou sem credenciais acadêmicas-- que trabalham diretamente com os jovens e adequar a infraestrutura dos centros de treinamento. $O$ discurso oficial dos clubes indica que os atletas são obrigados a estudar, mas a maioria dos clubes formadores não supervisiona ou acompanha a vida escolar dos mesmos (MELO, 20 I0). Em contraposição, na França, que também é um centro exportador de jogadores, a política governamental exige que haja compatibilidade entre a formação do jogador e seu processo de escolarização (DAMO, 2005). ${ }^{18}$ Importante salientar que o mercado de futebol no Brasil se desenvolveu na última década apresentando melhoria significativa na qualidade do processo de formação de atletas; isto inclui o oferecimento da educação escolar nos centros de treinamento de excelência (PAOLI et al., 20I0).

Os jovens que se alistam para disputar uma vaga nesse mercado possuem, em geral, algum capital futebolístico - técnicas esportivas incorporadas. Todavia, para tornar-se jogador profissional não basta apenas o capital futebolístico. Outras competências são necessárias ao longo do processo de formação. Além de suportar o regime de treinamento intenso, o atleta deve ter comportamento adequado à cultura do esporte (ser obediente aos superiores) e contar com um bom agenciamento comercial para ter acesso aos poucos postos de trabalhos disponíveis. 0 problema é que grande parte dos atletas que chega à categoria sub-20 não será aproveitada pelo mercado. Nesse caso, os malsucedidos, com baixo capital cultural, encontram dificuldades para se recolocarem no mercado fora do esporte (SOUZA et al., 2008). Todavia, no caso dos malsucedidos o diploma escolar seria uma credencial que facilitaria a recolocação profissional.

\section{CONCLUSÃO}

Os dados apresentados na literatura e nas pesquisas sobre o tema formam um paradoxo. Se o mercado do futebol profissional é altamente competitivo, com

18. Lembremos da polêmica que foi criada quando o jogador Henri, da seleção da França, apontou que a causa da grande habilidade dos jogadores brasileiros se devia ao pouco tempo gasto nos bancos escolares e o grande tempo que destinam à prática do futebol.

Cf. <http://observatorio.ultimosegundo.ig.com.br/artigos.asp?cod=389DAC00 I >. Acesso em: 12 fev. 2007. 
uma carreira que possui longevidade curta quando a comparamos com outras profissões e com uma pirâmide salarial tão desigual, por que há então uma grande demanda de jovens que buscam um lugar nesse limitado mercado? Em outras palavras, se é tão arriscado e difícil atingir a profissionalização e os salários em geral são baixos, por que investir tempo, energia e dinheiro no sonho de se tornar um jogador profissional?

Do ponto de vista da ação racional, poderíamos levantar a hipótese que o destino da maioria dos jovens que tentam a carreira de jogador, caso sejam malsucedidos, não seria diferente fora do futebol. $\bigcirc$ futebol pode ser para os membros das camadas populares, uma aposta individual e familiar que proporcione poucas perdas para aqueles que possuem poucas oportunidades de ascenção social e econômica. Além disso, é uma aposta que gera prestígio, sociabilidade e aventuras, normalmente, irrealizáveis do ponto de vista econômico para aqueles pertencentes às camadas populares no Brasil. ${ }^{19}$

A falta de oportunidades para as camadas populares associada a sedução que esse esporte exerce em nossa cultura, torna a produção de jogadores de futebol no Brasil uma empreitada bem-sucedida como demonstram os dados de transferência para o exterior ${ }^{20}$. Tal sucesso se deve a uma "combinação original":

a) um grande contingente de jovens do sexo masculino disponíveis;

b) um forte trabalho de formação corporal nos centros de treinamento no Brasil;

c) um mercado altamente competitivo e bem agenciado;

d) uma escola que é vista como desinteressante e representada como de baixa qualidade.

Apesar dos dilemas e dos pontos críticos que envolvem a formação de jogadores de futebol no Brasil, devemos reconhecer que o discurso da educação pelo esporte é duplamente potente em nossa sociedade. $\bigcirc$ esporte é representado socialmente como uma instituição educativa, associada à saúde e à qualidade de vida, e serve como uma saudável opção aos perigos do mundo da rua e/ou das drogas. A questão é: o que os filhos das camadas populares perdem com o investimento no futebol?

19. Nos trabalhos de campo realizados até o momento temos relatos emocionados das viagens de avião, pagamentos em dólar, restaurantes sofisticados, contato com outras culturas, relacionamentos com muitas mulheres etc.

20. Cf. $<w w w$.cbf.com.br $>$. 
Relationship between formation of young players in Brazil and education

ABSTRACT: The aim of this study is to discuss the relationship between professional soccer and education in Brazil. In the last six years, this country exported abroad a total of 6.648 soccer players. Among these players, 3.593 (or 54\%) went to Europe. We believe that we are dealing with an agency that recruits young male, generally from the lowest social strata, to play in internal or external soccer market. Besides, it configures a kind of business that supports an industry of professional formation, that may be in competition against basic schooling of these young athletes which dream about being professional soccer players. KEYWORDS: Soccer; education; formation of young players; school.

\section{Relación entre la formación de jugadores jóvenes en Brasil y la educación}

RESUMEN: El objetivo de este estudio es discutir la relación entre el fútbol profesional y el proceso de escolarización en Brasil. En los últimos seis años, este país exportó al extranjero un total de 6,648 jugadores de fútbol. Entre estos jugadores, 3.593 (54\%) emigraron a Europa. Creemos que se trata de uma agencia que recluta a hombres jóvenes, en general desde el más bajo estrato social, para jugar en el mercado del fútbol interno o externo. Además, se configura un tipo de negocio que soporta una industria de formación profesional, que puede competir contra la escolarización básica de estos jóvenes deportistas que sueñan con ser jugadores profesionales de fútbol.

PALABRAS CLAVE: Fútbol; educación; formación de jugadores jóvenes; escuela.

\section{REFERÊNCIAS}

ALCANTARA, H. A magia do futebol. Estudos Avançados, São Paulo, v. 20, n. 57, p. 297-3 I3, maio/ago. 2006. Disponível em: <http://www.scielo.br>. Acesso em: 12 dez. 2006.

ARCHETTI, E. Masculinidades: fútbol, tango y polo en la Argentina. Buenos Aires: Antropofagia, 2003.

BAENINGER, R. A. O Brasil na rota das migrações internacionais recentes. Jornal da Unicamp, Campinas, n. 226, p. 2, 25 ago. 2003. Disponível em: <http://www.unicamp.br/unicamp/ unicamp_hoje/ju/agosto2003/ju226pg2b.html>. Acesso em: 10 abr. 2005.

BARTHOLO, T. L.; SOARES, A. J. G. Identidade, negócio e esporte no mundo globalizado: o conflito entre Guga e os patrocinadores na Olimpíada de Sidney. Revista Brasileira de Ciências do Esporte, Campinas, v. 28, n. I, p. 55-72, set. 2006.

BOURDIEU, P. A escola conservadora: as desigualdades frente à escola e a cultura. In: NOGUEIRA, M. A.; CATANI, A. (Org.). Pierre Bourdieu: escritos de educação. Petrópolis: Vozes, 1998. p. 39-65. 
CARVALHO, C. A.; GONÇALVES, J. C. A mercantilização do futebol brasileiro: instrumentos, avanços e resistências. Cadernos Ebape, Rio de Janeiro, v. 4, n. 2, jun. 2006. Disponível em: <http://www.ebape.fgv.br/cadernosebape/asp/dsp_texto_completo.asp?cd_pi=4|872| >. Acesso em: 22 nov. 2006.

CHRISTENSEN, M.K; SØRENSEN, J.K. Sport or school? Dreams and dilemmas for talented young Danish football players. European Physical Education Review, London, v. I 5, n. I, p. | | 5- | 37, 2009. Disponível em < http://epe.sagepub.com/cgi/content/abstract// 5/I / | 5>. Acesso em: 5 mar. 2010.

COGO, D. Mídia, imigração e interculturalidade: mapeando as estratégias de midiatização dos processos migratórios e das falas imigrantes no contexto brasileiro. Fronteiras Estudos Midiáticos, São Leopoldo, v. 4, n. 2, p. 145-163, 2002.

CORROCHANO, M. C.; NAKANO, M. Jovens, mundo do trabalho e escola. In: SPOSITO, M. P. (Coord.). Juventude e escolarização: 1980- 1998. Brasília: MEC, 2002. p. 95- I34. (Estado do Conhecimento, n. 7).

COSTA, M. da; KOSLINSKI, M. C. Entre o mérito e a sorte: escola, presente e futuro na visão de estudantes do ensino fundamental do Rio de Janeiro. Revista Brasileira de Educação, Rio de Janeiro, v. II , n. 3 I , p. I33-2II, abr. 2006. Disponível em: <http://www.scielo.br/ scielo >. Acesso em 22 abr. 2010.

CUCHE, D. A noção de cultura nas ciências sociais. São Paulo: Edusc, 1999.

DABSCHECK, B. The globe at their feet: FIFA's new employment rules - II. Sport in Society, Oxford, v. 9, n. I, p. I- I8, jan. 2006.

DAMO, A. Do dom a profissão: uma etnografia do futebol de espetáculo a partir da formação de jogadores no Brasil e na França. 2005. 435 f. Tese (Doutorado em Antropologia Social)Instituto de Filosofia e Ciências Humanas, Universidade Federal do Rio Ggrande do Sul, Porto Alegre, 2005.

Paulo: Hucitec, 2007.

Do dom à profissão: a formação de futebolistas no Brasil e na França. São

DIETSCHY, P. Dos desafios políticos: los traspasos de jugadores y la descolonización deportiva de África. Vanguardia Dossier, Barcelona, v. 20, p. 78-89, jul./set. 2006.

FUSCO, W. Conexão origem-destino: migrantes brasileiros no exterior. In: ENCONTRO NACIONAL DE ESTUDOS POPULACIONAIS, I5., 2006, Caxambu. Anais... Caxambu: ABEP, 2006. Disponível em: http://www.abep.nepo.unicamp.br/encontro2006/docspdf/ ABEP2006_638.pdf. Acesso em: Acesso em: 12 dez. 2006.

GUTTMANN, A. Games and empires: modern sports and cultural imperialism. Nova York: Columbia University Press, 1994. 
HALL, S. Da diáspora: identidades e mediações culturais. Brasília: Ed. da UFMG, 2003.

HELAL, R. Passes e impasses: futebol e cultura de massa no Brasil. Petrópolis: Vozes, 1997. ; SOARES, A. J. G.; SALLES, J. G. C. Futebol. In: DACOSTA, L. P. (Org.). Atlas do esporte no Brasil. Rio de Janeiro: Shape, 2005. p. 257-259.

JACOBS, C. S.; DUARTE, F. Futebol exportação. Rio de Janeiro: SENAC, 2006.

LEONCINI, M. P.; SILVA, M. T. Entendendo o futebol como negócio: um estudo exploratório. Gestão e Produção, São Carlos, v. 12, n. I, p. I I-23, jan./abr. 2005.

MACHADO, I. J. Estado-nação, identidade-para-o-mercado e representações de nação. Revista Antropologia, São Paulo, v. 47, n. I, p. 207-233, 2004. Disponível em: < http:// www.scielo.br/scielo.php?script =sci_arttext\&pid =S0034-770 I 2004000 I $00006>$. Acesso em: fev. 2005.

MAGEE, J.; SUGDEN J. "The world at their feet": professional football and international labor migration. Journal of Sport and Social Issues, Thousand Oaks, v. 26, n. 4, p. 42I-437, nov. 2002.

MANDELL, R. Sport: a cultural history. New York: Columbia University, 1984.

MCGILLIVRAY, D; MCINTOSH, A. Football is my life: theorizing social practice in the Scottish professional football field. Sport in Society, Abingdon, v. 9, n. 3, p. 37I-387, jul. 2006. Disponível em: http://www.informaworld.com/smpp/content $\sim \mathrm{db}=\mathrm{all} \sim$ content $=\mathrm{a} 747764332$. Acesso em: 12 mar. 2010.

MELO, L. B. S. Formação e escolarização de jogadores de futebol no Estado do Rio de Janeiro. 2010. 72 f. Dissertação (Mestrado em Educação Física)-Universidade Gama Filho, Rio de Janeiro, 2010.

PAOLI, P. B. Os estilos de futebol e os processos de seleção e detecção de talentos. 2007. 178 f. Tese (Doutorado em Educação Física)-Universidade Gama Filho, Rio de Janeiro, 2007.

et al. Representações identitárias no processo de seleção de talentos. Movimento, Porto Alegre, v. 16, n. 4, p. 135-150, out./dez. 2010.

PEREIRA, L. A. M. Footballmania: uma história social do futebol no Rio de Janeiro, I 902- 1938. Rio de Janeiro: Nova Fronteira, 2000.

POLI, R. Identidades nacionales y globalización. Vanguardia Dossier, Barcelona, v. 20, p. 47-50, jul./set. 2006.

PRONI, M. W. A metamorfose do futebol. Campinas: Ed. da Unicamp, 2000.

RIAL, C. S. Futebolistas brasileiros na Espanha: emigrantes porém... Revista de Dialectología y Tradiciones Populares, Madrid, v. 6I, n. 2, p. 163-190, jul./dez. 2006. 
SCHWARTZMAN, S. As causas da pobreza. Rio de Janeiro: Ed. da FGV, 2004.

. Programas sociais voltados à educação no Brasil. Sinais Sociais, Rio de Janeiro, v. I, n. I, p. | |4-|45, maio/ago. 2006.

SEGNINI, L. R. P. Educação e trabalho: uma relação tão necessária quanto insuficiente. São Paulo Em Perspectiva, São Paulo, v. I4, n. 2, p. 72-81, abr./ jun. 2000.

SOARES, A. J.; LOVISOLO, H. R. Futebol: A construção histórica do estilo nacional. Revista Brasileira de Ciências do Esporte, Campinas, v. 25, n. I, p. I29-|43, set. 2003.

SOUZA, C. A. M. et al. Difícil reconversão: futebol, projeto e destino em meninos brasileiros. Horizontes Antropológicos, Porto Alegre, v. I4, n. 30, p. 85-I I I, dez. 2008. Disponível em: <http://www.scielo.br >. Acesso em: 05 mar. 2009.

SOUTO, S. M. Futebol: entre o simbólico e o mercado. In: OLIVEIRA, J.; GARGANTA, J.; MURAD, M. Futebol: de muitas cores e sabores. Porto: Campo das Letras, 2004. p. I19135. (Saberes do Desporto).

TOLEDO, L. H. Lógicas do futebol. São Paulo: Hucitec, 2002.

Recebido: 14 jul. 2010 Aprovado: 09 fev. 201।

Endereço para correspondência: Antonio Jorge $\mathrm{G}$. Soares Avenida Pasteur 250, $2^{\circ}$ andar - CEP: 22.290-240 Campus da Praia Vermelha, Rio de Janeiro, Brasil. 